\title{
Accumulation of Regulatory T Cells in Triple Negative Breast Cancer Can Boost Immune Disruption
}

\author{
Asmaa M Zahran (iD ${ }^{\prime}$ \\ Omnia El-Badawy (D) ${ }^{2}$ \\ Lamiaa M Kamel (1D ${ }^{3}$ \\ Amal Rayan (iD) \\ Khalid Rezk ${ }^{5}$ \\ Mona $\mathrm{H}$ Abdel-Rahim (iD ${ }^{2}$ \\ 'Department of Clinical Pathology, South \\ Egypt Cancer Institute, Assiut University, \\ Assiut, Egypt; ${ }^{2}$ Department of Medical \\ Microbiology and Immunology, Faculty of \\ Medicine, Assiut University, Assiut, Egypt; \\ ${ }^{3}$ Department of Clinical Pathology, \\ Faculty of Medicine, Zagazig University, \\ Zagazig, Egypt; ${ }^{4}$ Clinical Oncology \\ Department, Faculty of Medicine, Assiut \\ University, Assiut, Egypt; ${ }^{5}$ Surgical \\ Oncology Department, South Egypt \\ Cancer Institute, Assiut University, \\ Assiut, Egypt
}

Background and Aim: The present study was conducted to evaluate the number of Tregs in triple negative breast cancer (TNBC), in normal breast parenchyma and in the peripheral blood of these patients and controls, in addition to their correlations with the clinicopathologic features and the outcomes of TNBC.

Methods: Thirty adult treatment-naïve women with non-metastatic TNBC were recruited. In addition, 20 ages matched healthy females participated as a control group. Peripheral blood samples were collected from all participants in tubes containing heparin, fresh tumor tissues were also obtained from all patients undergoing surgery, and 20 normal breast tissue samples were obtained from the same patients' areas adjacent to the safety margins; all these samples were taken for flow cytometric detection of Tregs.

Results: The mean percentages of $\mathrm{CD} 4^{+} \mathrm{CD} 25^{\text {thigh }} \mathrm{T}$ cells and Tregs were higher in TNBC peripheral blood than healthy controls and in malignant tissue than normal tissue. Moreover, the frequencies of tumor-infiltrating $\mathrm{CD}^{+} \mathrm{T}$ cells and Tregs were exceeding those in the peripheral blood of cancer patients. Only tumor-infiltrating Tregs have shown increasing levels with the increase in the tumor size and were significantly higher in patients with local recurrences than those without recurrence. In addition, Tregs showed significant inverse relation with DFS and direct relation with the level of the peripheral Tregs.

Conclusion: The findings of the current study support the possibility that TNBC microenvironment conveys specific characteristics on Tregs distinguishing them from those in normal breast tissue or Tregs in peripheral blood, improving the capabilities of tumorinfiltrating Tregs to enhance tumor growth, local recurrence and reduce the DFS.

Keywords: triple negative breast cancer, Tregs, disease free survival, recurrences

\section{Introduction}

Significant attention has been given to regulatory $\mathrm{T}$ cells (Tregs) expressing the transcription factor fork head box protein P3 (Foxp3). ${ }^{1}$ Tregs have a fundamental role in sustaining immunological tolerance and controlling autoimmunity. ${ }^{2}$ They act by controlling the activation and differentiation of $\mathrm{CD}^{+}$Th cells and $\mathrm{CD} 8^{+}$ cytotoxic $\mathrm{T}$ cells in response to environmental, autogenous, or tumor associated antigens. Studies have confirmed that Tregs have opposing actions in cancer immunity leading to immune evasion of cancer cells and implying a functional impact on tumor progression and metastasis. ${ }^{3-5}$

Interestingly, the clinical relevance of tumor-infiltrating Tregs has been found ambiguous. For instance, a high Tregs density in hepatocellular carcinoma is
Correspondence: Amal Rayan Email amal3774rayan@gmail.com; amalrayan@aun.edu.eg 
predictive of poor prognosis, in line with the hypothesis that Tregs enhance tumor progression through tumor-specific $\mathrm{T}$ cell suppression. On the other hand, improved clinical outcome in other tumors as colorectal carcinoma is associated with a high Tregs density. These contrasting results indicate that the role of Tregs in tumor development may vary substantially according to the affected site. $^{6}$

Similarly, Tregs were suggested to be correlated with good outcome of breast cancer in one study, ${ }^{7}$ while other studies revealed that Tregs were associated with poor outcome of breast cancer. ${ }^{8,9}$

Triple negative breast cancer (TNBC) is a type of breast tumors that do not express estrogen receptors (ER), progesterone receptors (PR), and human epidermal growth factor receptor 2 (HER2) on the surface. ${ }^{10}$ Patients with this TNBC have enhanced risk of metastasis and relapse, and cannot utilize targeted therapy. ${ }^{11}$

Increased tumor-infiltrating-lymphocytes (TILs) in TNBC support the high immunogenic nature of this subtype of breast cancer. ${ }^{12-14}$

It is not evident whether the Tregs found intra-tumoral are comparable to those in normal tissues or in the peripheral blood. The tumor microenvironment might imprint distinctive transcriptional and functional characteristics upon Tregs. ${ }^{15,16}$ Recently, peripheral blood Tregs represented the main source of intra-tumoral Tregs in human breast cancers and that their response to cytokine signaling indicates intra-tumoral immunosuppressive possibility and predicts clinical outcome. ${ }^{17}$

So far, the prognostic value of Tregs in breast cancer is still controversial, and further studies are needed to fully understand its significance. ${ }^{18-22}$ The present study was conducted to evaluate the number of Tregs in TNBC, in normal breast parenchyma and in the peripheral blood of these patients and controls, in addition to their correlations with the clinico-pathologic features and the outcomes of TNBC.

\section{Patients and Methods}

Thirty adult treatment-naïve women undergoing surgical treatment of non-metastatic TNBC in the South Egypt Cancer Institute and Clinical Oncology Department, Assiut University Hospital were enrolled. The clinical and histopathological characteristics of the patients are shown in Table 1. In addition, 20 age matched healthy females participated as a control group.

\section{Ethical Statement}

The Committee of Medical Ethics of faculty of medicine, Assiut University reviewed and accepted the research proposal (IRB no. 17300416) and the study was done in compliance with the ethical guidelines of the Declaration of Helsinki 1975. Informed consent was obtained from all research participants before sharing in the study.

\section{Surgical Procedures}

After confirmation of breast cancer by needle biopsy, patients were offered preoperative assessment by multisclice cut scans of chest and abdomen, bone scan, and tumor markers including CA15-3, and CEA in order to exclude metastatic cases, and then patients underwent either modified radical mastectomy (MRM), or breast conservative surgery (BCS).

\section{Adjuvant Therapy}

After surgery, pathologic assessment of tumor type, size, grade, lymph node (LN) status was done, followed by immunophenotyping to ensure negativity of estrogen and progesterone receptors, and HER2neu. All patients received adjuvant chemotherapy according to standardized guidelines, patients with $\mathrm{BCS},>\mathrm{T} 2$ lesions, positive LN, positive surgical margins, and perineural invasion were treated with 3 DCRT with doses ranging from 40 to 66 Gy over 15-33 fractions.

\section{Follow Up}

TNBC women in our study were followed up monthly by clinical examinations for the first 2 years, then every 3-6 months for additional 3 years, then yearly later on, MSCT chest and abdomen and tumor marker were done every 3 months in the first 2 years, then every 6 months in the next 3 years, and then yearly later on, bone scan was done when indicated (bone pain, rising ALP, rising serum calcium, etc.), these follows ups continued until disease recurrence or death of patients to determine their disease free survival (DFS).

\section{Sample Processing}

Peripheral blood samples were collected from all participants in tubes containing heparin. Fresh tumor tissues were also obtained from all patients undergoing surgery for primary breast cancer immediately after surgery. In addition, 30 apparently normal breast tissue samples were obtained from the same patients from areas adjacent to the safety margins (20 tissue samples were areas devoid of any abnormalities; whether inflammatory or benign lesions and subsequently 
Table I Clinical and Histopathological Characteristics of the TNBC Patients' Group

\begin{tabular}{|l|l|}
\hline Characteristics & Frequency \\
\hline $\begin{array}{l}\text { Age(years) } \\
\text { mean } \pm \text { SD }\end{array}$ & $50.4 \pm 10.4$ \\
Range & $28-77$ \\
\hline $\begin{array}{l}\text { Pathologic type } \\
\text { IDC }\end{array}$ & $28(98.3 \%)$ \\
ILC & $2(6.7 \%)$ \\
\hline Histological grade ${ }^{a}$ & \\
GI & $1(3.3 \%)$ \\
G2 & $25(83.3 \%)$ \\
G3 & $4(13.3 \%)$ \\
\hline Tumor size & \\
TI & $4(13.3 \%)$ \\
T2 & $19(63.3 \%)$ \\
T3 & $7(23.3 \%)$ \\
\hline Lymph node stage & \\
NO & $14(46.7 \%)$ \\
NI & $14(46.7 \%)$ \\
N3 & $2(6.7 \%)$ \\
\hline Surgery & \\
MRM & $22(73.3 \%)$ \\
BCS & $8(26.7 \%)$ \\
\hline Local recurrence & $39 \pm 3.1(95 \% \mathrm{Cl}=33-45)$ \\
mFS (months) & $32 \pm 2.1(95 \% \mathrm{Cl}=28-36.1)$ \\
\hline median \pm SE & \\
\hline
\end{tabular}

Notes: Data expressed as mean \pm SD/SE or number (percentage). ${ }^{a}$ The Nottingham Combined Histologic Grade (Modified Scarff-Bloom-Richardson Grade) (Ellis et al, 2003).

Abbreviations: TNBC, triple negative breast cancer; IDL, infiltrating ductal carcinoma; ILC, infiltrating lobular carcinoma; G, grade; MRM, modified radical mastectomy; BCS, breast conservative surgery; DFS, disease free survival.

included for comparison, while the other remaining 10 sample tissues were found to have abnormalities subsequently, were excluded). The tumor tissues were mechanically fragmented to prepare single-cell suspension. The cell suspensions were filtered through cell strainers $(100 \mu \mathrm{M})$. The contaminating red blood cells were removed by incubation with lysing solution for 5 minutes at $4^{\circ} \mathrm{C}$, and the resultant suspension was washed twice with phosphate buffered saline (PBS).

\section{Flow Cytometric Detection of Regulatory T Cells in Peripheral Blood and Breast \\ Tissue}

Fluoroisothiocyanate (FITC)-conjugated-Foxp3 (clone PCH101, eBioscience, Invitrogen, Thermofisher, US), phycoerythrin (PE) conjugated-CD25 (clone 2A3, Becton Dickinson (BD) Bioscience, CA, USA) and peridinium-chlorophyll-protein (Per-CP)-conjugated-CD4 (clone SK3, BD Bioscience, CA, USA) were used to detect Tregs. For assessment of Tregs, $1 \times 10^{6}$ cells of the breast tissue sample in $100 \mu \mathrm{L}$ of PBS in one tube and $50 \mu \mathrm{L}$ of blood sample in another tube were incubated with $5 \mu \mathrm{L}$ of $\mathrm{CD} 4, \mathrm{CD} 25$ for 15 minutes at $4{ }^{\circ} \mathrm{C}$ in the dark. Following incubation, red blood cells lysis, washing with PBS then addition of fixation solution to fix the cells and incubation for 10 minutes were done. After that, the cells were washed with PBS, and permeabilization solution (IntraSure ${ }^{\mathrm{TM}} \mathrm{kit}, \mathrm{BD} \mathrm{CA}, \mathrm{USA}$ ) and $5 \mu \mathrm{L}$ of Foxp3 were added and incubated for 20 minutes. The cells were then resuspended in PBS and analyzed by FACSCalibur flow cytometry with Cell Quest software (Becton Dickinson Biosciences, USA). An isotypematched IgG negative control was used for each sample. Forward and side scatter histogram was used to define the lymphocytes population. Then $\mathrm{CD} 4^{+}$cells were gated. Total $\mathrm{CD} 4^{+} \mathrm{CD} 25^{+ \text {low }}, \mathrm{CD} 4^{+} \mathrm{CD} 25^{+ \text {High }}$ and

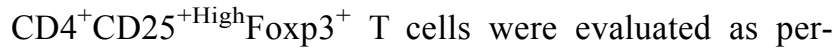
centages of $\mathrm{CD}^{+}$cells in both blood and tumor tissue as shown in Figures 1 and 2, respectively.

\section{Statistical Analysis}

Numerical data was expressed as mean, median and standard deviation or standard error mean. Qualitative data were presented as number and percentage. The independent sample $t$-test and One-way ANOVA were used to assess the statistical differences between groups. Paired-t-test was applied to compare the percentages of cells between tumor tissue and peripheral blood. Pearson correlation was used to evaluate the strength of linear association between variables. The disease-free survival (DFS) was calculated using Kaplan-Meier curve and the receiver operating characteristic (ROC) curve was employed to estimate the accuracy of tumor-infiltrating Tregs in prediction of DFS ( $\geq 3$ years). All analysis was performed by SPSS 20.0 software (SPSS, Inc., Chicago, IL, USA).

\section{Results}

\section{Characteristics of the Patients' Group}

The patients' ages ranged from 28 to 77 years with a mean of $50.4 \pm 10.4$. The tumor size in most of the patients was T2 $(63.3 \%)$. Most of the patients were either N0 $(46.7 \%)$ 

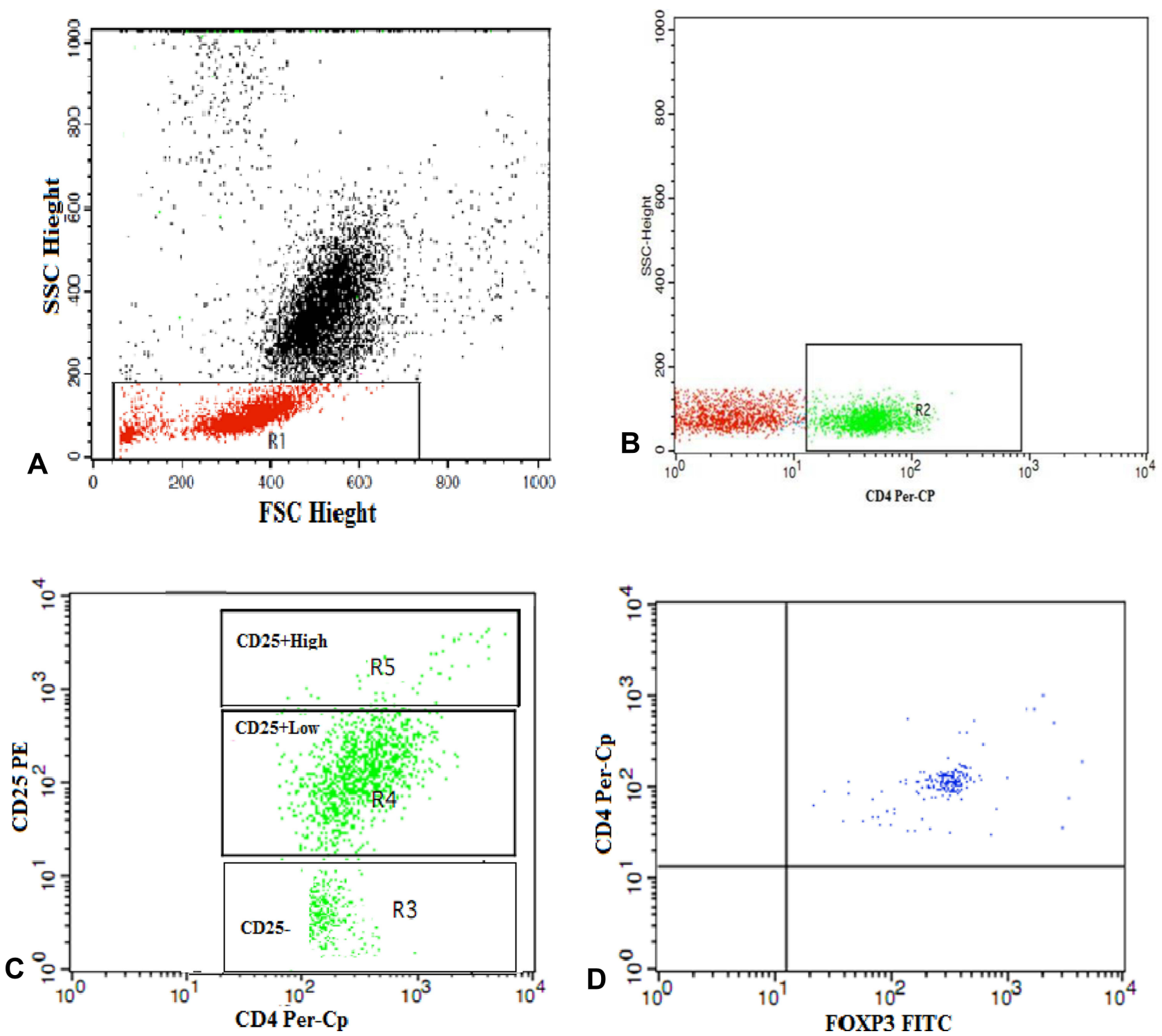

Figure I Gating strategy to identify regulatory T cells in peripheral blood. (A) The lymphocyte population was identified based on the forward and side scatter characteristics and was selected by RI. (B, C) CD4 cells among the gated lymphocytes were selected by (R2) for further analysis on the basis of the level of CD25 expression. (R3), (R4) and (R5) were drawn to identify CD4 ${ }^{+}$cells with no, low and high CD25 expression, respectively. (D) Dot plot representing FoxP3 expression among the $\mathrm{CD} 4^{+} \mathrm{CD} 25^{\text {thigh }}$ cells to detect Tregs $\left(\mathrm{CD} 4^{+} \mathrm{CD} 25^{\text {thigh }}\right.$ Fox $^{+} 3^{+}$).

or N1 (46.7\%). Pathologic examination of breast cancer tissue showed that the majority was infiltrating ductal carcinoma (IDC) (98.3\%) of G2 (83.3\%). Modified radical mastectomy (MRM) was done in $73.3 \%$ of patients, whereas breast conservative surgery (BCS) in $26.7 \%$. Local recurrence was observed in $16.7 \%$ of them. The median DFS \pm SE was $32 \pm 2.1$ months (95\% CI $=28-36.1$ ) (Table 1).

\section{Assessment of Tregs Levels in Peripheral Blood and Breast Cancer Tissue of Patients with TNBC in Comparison with the Control Group}

As shown in Table 2, while the level of total $\mathrm{CD} 4^{+} \mathrm{T}$ cells in the peripheral blood was significantly lower in patients than healthy controls, their level in the malignant breast cancer tissue was higher than that in the normal tissue. The mean 

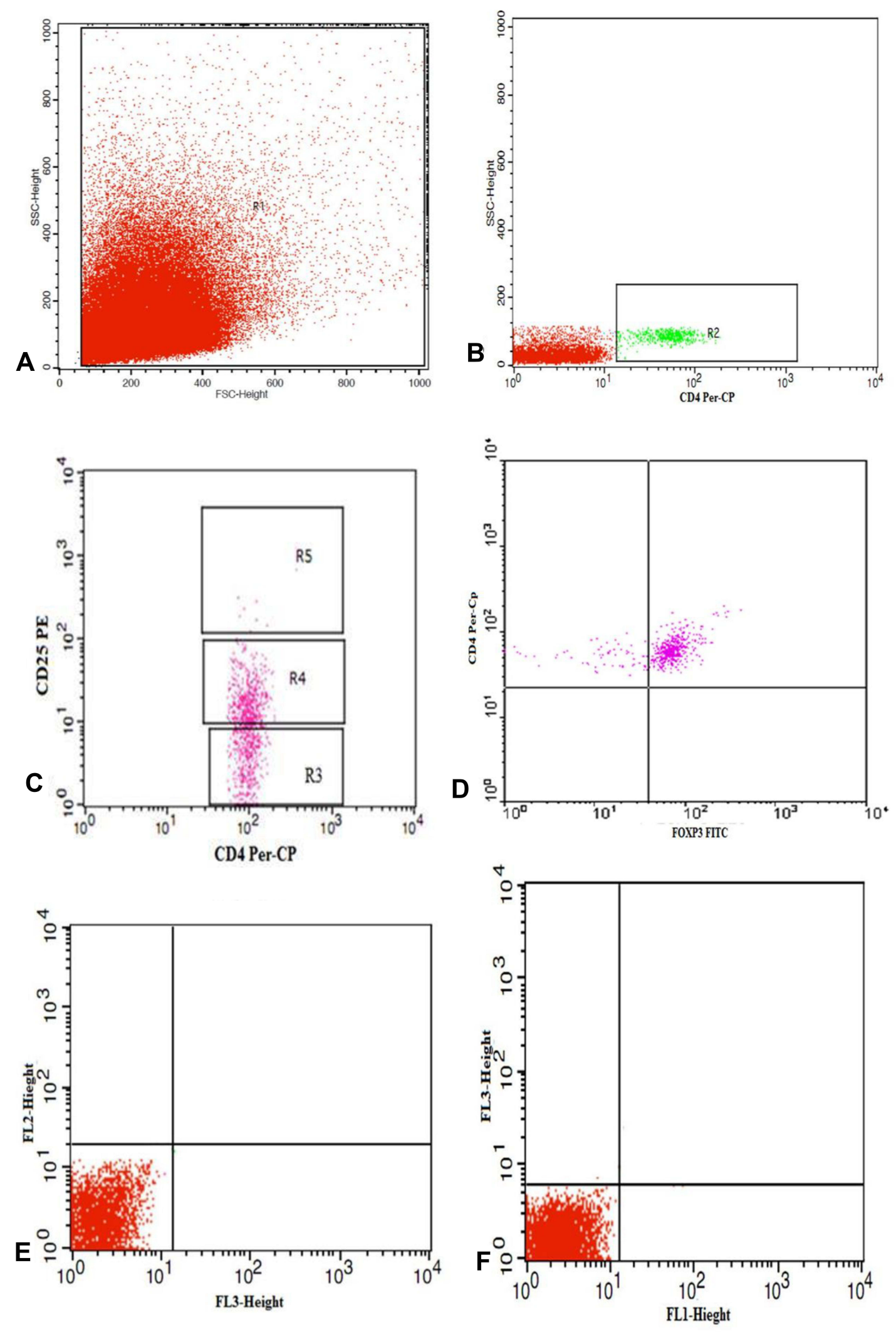

Figure 2 Gating strategy to identify regulatory T cells in tumor tissue. (A) The lymphocyte population was selected by RI. (B, C) CD4 ${ }^{+}$cells among the gated lymphocytes were selected by (R2) then (R3), (R4) and (R5) were drawn to identify CD4 $4^{+}$cells with no, low and high CD25 expression, respectively. (D) Dot plot representing FoxP3 expression among the $\mathrm{CD} 4^{+} \mathrm{CD} 25^{\text {thigh }}$ cells to detect Tregs $\left(\mathrm{CD} 4^{+} \mathrm{CD} 25^{\text {high }}\right.$ FoxP3 $\left.{ }^{+}\right)$. (E, F) Representative dot plots of isotype control. 
Table 2 Tregs Levels in Peripheral Blood and Breast Cancer Tissue of Patients with TNBC in Comparison with the Control Group

\begin{tabular}{|c|c|c|c|}
\hline Peripheral Blood Parameters (\%) & Patients $(\mathbf{N}=30)$ & Controls $(\mathbf{N}=\mathbf{2 0})$ & p-value* \\
\hline $\mathrm{CD}^{+} \mathrm{T}$ cells & $40.1 \pm 1$ & $51.3 \pm 1$ & $<0.0001$ \\
\hline $\mathrm{CD}^{+} \mathrm{CD} 25^{\text {thigh }} \mathrm{T}$ cells & $7.1 \pm 0.5$ & $4.3 \pm 0.2$ & $<0.0001$ \\
\hline $\mathrm{CD}^{+} \mathrm{CD} 25^{+ \text {high }} \mathrm{FoxP} 3^{+}$Tregs & $2.3 \pm 0.1$ & $1.7 \pm 0.1$ & $<0.000$ I \\
\hline Tissue parameters (\%) & Malignant tissue $(\mathrm{N}=30)$ & Normal tissue $(\mathrm{N}=\mathbf{2 0})$ & $p$-value** \\
\hline $\mathrm{CD}^{+} \mathrm{T}$ cells & $58.2 \pm 2.7$ & $46 \pm 2.2$ & 0.031 \\
\hline $\mathrm{CD}^{+} \mathrm{CD} 25^{\text {thigh }} \mathrm{T}$ cells & $6.7 \pm 0.2$ & $4.5 \pm 0.2$ & $<0.0001$ \\
\hline $\mathrm{CD}^{+} \mathrm{CD} 25^{\text {thigh }} \mathrm{FoxP} 3^{+}$Tregs & $6.6 \pm 0.4$ & $3.2 \pm 0.1$ & $<0.0001$ \\
\hline Parameter (\%) & Tissue lymphocytes $(\mathrm{N}=30)$ & Peripheral lymphocytes $(\mathrm{N}=\mathbf{2 0})$ & $p$-value $* *$ \\
\hline $\mathrm{CD}^{+} \mathrm{T}$ cells & $58.2 \pm 2.7$ & $40.1 \pm 1.4$ & $<0.0001$ \\
\hline $\mathrm{CD}^{+} \mathrm{CD} 25^{\text {thigh }} \mathrm{T}$ cells & $6.7 \pm 0.2$ & $7.1 \pm 0.5$ & 0.4 \\
\hline $\mathrm{CD}^{+} \mathrm{CD} 25^{+ \text {high }}$ FoxP $3^{+}$Tregs & $6.6 \pm 0.4$ & $2.3 \pm 0.1$ & $<0.0001$ \\
\hline
\end{tabular}

Notes: Data presented as mean \pm SE, *Independent sample $t$-test, **Paired-t test, significant $p$-value $<0.05$.

percentages of $\mathrm{CD}^{+} \mathrm{CD} 25^{\text {thigh }} \mathrm{T}$ cells and Tregs were higher in TNBC than healthy controls and in malignant tissue than normal tissue. Moreover, the frequencies of tumor-infiltrating $\mathrm{CD}^{+} \mathrm{T}$ cells and Tregs were exceeding those in the peripheral blood of cancer patients $(p<0.0001)$.

\section{Relations Between Tumor-Infiltrating and Peripheral Blood Tregs and the Clinicopathologic Characteristics of Patients with TNBC}

$\mathrm{CD} 4{ }^{+} \mathrm{CD} 25^{+}$subsets and Tregs have shown no significant associations with most of the tested clinicopathologic characteristics in both breast tissue and peripheral blood. Only tumor-infiltrating Tregs have shown increasing levels with the increase in the tumor size $(p<0.0001)$ and were significantly higher in patients with local recurrences than those without recurrence $(p=0.001)$, (Tables 3 and 4, Figure 3).

\section{Relations Between Tumor-Infiltrating Tregs and the DFS}

Among all tested tumor-infiltrating $\mathrm{CD} 4{ }^{+} \mathrm{CD} 25^{+}$subsets, only Tregs showed significant inverse relation with DFS $(\mathrm{r}=-0.6, p<0.0001)$ and direct relation with the level of the peripheral Tregs $(r=0.4, p=0.046)$. The predictive accuracy of the levels of tumor-infiltrating Tregs in assessing the DFS period ( $\geq 3$ years) was estimated using the ROC curve. Tumor-infiltrating Tregs showed good predictive accuracy [Area under the curve (AUC) $=0.9 \pm 0.06,95 \%$ confidence interval $(\mathrm{CI}): 0.79-1.00, p=0.001)$ at the cutoff point $6.91 \%$ with a sensitivity of $86 \%$ and a specificity of
$87 \%$. The mean DFS for TNCB patients with tumor-infiltrating Tregs $<6.91 \%$ was $47.8 \pm 4$ months $(95 \% \mathrm{CI}=40.15-$ 55.43), while for those with Tregs $>6.91 \%$ was $27.1 \pm 3$ months $(95 \% \mathrm{CI}=21.8-32.4), \log \mathrm{rank}=17.36,(p<0.001)$ (Figure 4). Of the 30 TNBC patients, 19 had tumor-infiltrating Tregs level $<6.91 \%$, only one of them displayed local recurrence $(5 \%)$, and 11 had Tregs level $>6.91 \%$, six of them showed local recurrences $(55 \%)(p=0.004)$.

\section{Discussion}

TNBC is an aggressive type of breast cancer characterized by poor prognosis and lack of targeted therapy. ${ }^{23}$ TNBC has higher immunogenicity and tends to have higher Tregs infiltration than other subtypes. ${ }^{22,24,25}$

Inconsistent findings on the influence and prognostic value of Tregs in TNBC has been reported in previous reports. $^{18-22}$

In this study, the mean percentages of Tregs were higher in the peripheral blood of TNBC patients than healthy controls and in tumor tissue than normal breast parenchyma. Consistent with our findings, Wang and Huang reported significantly increased serum levels of CD4+CD25+Foxp3 + Tregs in patients with breast cancer compared with healthy individuals. $^{26}$ In addition, Plitas et al. ${ }^{16}$ found increased Tregs in breast cancer tissue as compared to normal breast parenchyma and peripheral blood. Furthermore, breast tumor cells utilize immune regulatory cells such as Treg and different immunosuppressive pathways involving CD39, PD-1 and CTLA-4 molecules in creating disturbed immune environment for them to survive. ${ }^{27}$ 
Table 3 Relations Between Tumor-Infiltrating Tregs and the Clinicopathologic Characteristics of Patients with TNBC

\begin{tabular}{|c|c|c|c|c|}
\hline Parameters & $\mathrm{CD}^{+}{ }^{+} \mathrm{T}$ Cells & CD4+CD25+ low $\mathrm{T}$ Cells & $\mathrm{CD}^{+}{ }^{+} \mathrm{CD} 25^{\text {high }} \mathrm{T}$ Cells & Tregs \\
\hline \multicolumn{5}{|l|}{ Tumor size* } \\
\hline TI $(n=4)$ & $51 \pm 9$ & $19.6 \pm 2$ & $6.8 \pm 0.8$ & $5.1 \pm 1.7$ \\
\hline $\mathrm{T} 2(\mathrm{n}=19)$ & $58.6 \pm 4$ & $19.3 \pm 0.8$ & $6.7 \pm 0.3$ & $6.0 \pm 0.2$ \\
\hline T3 $(n=7)$ & $61.2 \pm 5$ & $19.3 \pm 2$ & $6.7 \pm 0.5$ & $9.2 \pm 0.8$ \\
\hline$p$-value & 0.6 & 0.99 & 0.99 & $<0.0001$ \\
\hline \multicolumn{5}{|c|}{ Lymph node stage $\mathrm{a}_{*}$} \\
\hline No $(n=15)$ & $59 \pm 3$ & $19 \pm 1$ & $6.6 \pm 0.3$ & $6.3 \pm 0.5$ \\
\hline$N I(n=14)$ & $56.6 \pm 5$ & $19 \pm 0.9$ & $6.7 \pm 0.3$ & $7 \pm 0.6$ \\
\hline N3 $(n=2)$ & $54.6 \pm 3$ & $20 \pm 1$ & $7 \pm 0.4$ & $6.2 \pm 0.4$ \\
\hline$p$-value & 0.9 & 0.97 & 0.97 & 0.6 \\
\hline \multicolumn{5}{|l|}{ Pathologic type ${ }^{* * *}$} \\
\hline IDC $(n=28)$ & $58.7 \pm 3$ & $19.2 \pm 0.7$ & $6.7 \pm 0.2$ & $6.6 \pm 0.4$ \\
\hline ILC $(n=2)$ & $51.6 \pm 23$ & $21.2 \pm 3$ & $7 \pm 0.9$ & $6.7 \pm 0.2$ \\
\hline$p$-value & 0.5 & 0.4 & 0.4 & 0.98 \\
\hline \multicolumn{5}{|c|}{ Histological grade ${ }^{a_{*}}$} \\
\hline GI $(n=I)$ & $72 \pm 0$ & $26.1 \pm 0$ & $9 \pm 0$ & $2.8 \pm 0$ \\
\hline G2 $(n=25)$ & $56.4 \pm 3$ & $19.3 \pm 0.7$ & $6.7 \pm 0.3$ & $6.7 \pm 0.4$ \\
\hline G3 $(n=4)$ & $65.9 \pm 4$ & $17.9 \pm 2$ & $6.3 \pm 0.6$ & $7 \pm 1$ \\
\hline$p$-value & 0.3 & 0.1 & 0.1 & 0.1 \\
\hline \multicolumn{5}{|l|}{ Type of surgery* } \\
\hline MRM $(n=23)$ & $56 \pm 3$ & $19 \pm 0.6$ & $6.6 \pm 0.2$ & $6.9 \pm 0.5$ \\
\hline $\operatorname{BCS}(n=7)$ & $63 \pm 6$ & $19.3 \pm 2$ & $6.7 \pm 0.6$ & $6.4 \pm 0.2$ \\
\hline Simple mast. $(n=1)$ & $72 \pm 0$ & $26 \pm 0$ & $9 \pm 0.2$ & $2.8 \pm 0$ \\
\hline$p$-value & 0.4 & 0.1 & 0.1 & 0.1 \\
\hline \multicolumn{5}{|l|}{ Recurrence** } \\
\hline No $(n=23)$ & $58.6 \pm 3$ & $18.7 \pm 0.8$ & $6.5 \pm 0.3$ & $6 \pm 0.3$ \\
\hline Yes $(n=7)$ & $57 \pm 6$ & $21.3 \pm 1$ & $7.4 \pm 0.4$ & $8.8 \pm 0.7$ \\
\hline$p$-value & 0.8 & 0.1 & 0.1 & 0.001 \\
\hline
\end{tabular}

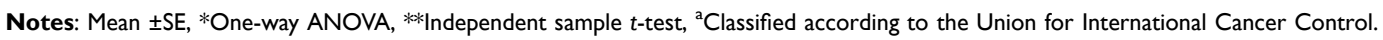

Abbreviations: IDC, invasive ductal carcinoma; ILC, invasive lobular carcinoma; MRM, modified radical mastectomy; BCS, breast-conserving surgery; mast., mastectomy; G, grade; N, lymph node stage; T, tumor stage.

The increased tumor-infiltrating Tregs could be explained by expression of homing of receptors on Tregs that directs the migration of distinct populations to certain tissues $^{28}$ and regional extension of pre-existing tissue resident Tregs. ${ }^{16}$ In addition, powerful stimulation of $\mathrm{T}$ cell receptors is needed for Treg cell activation, proliferation and inhibitory function. ${ }^{29}$ Additionally, chemokine signaling, and cell migration were found to be the main single group of genes enriched in tumor-infiltrating Tregs. ${ }^{16}$

The tumor-infiltrating Tregs showed significant direct relation with the level of Tregs in the peripheral blood. Similarly, Cai et al. ${ }^{30}$ reported that the level of CD25
+Foxp3+ Tregs in circulating CD4+T cells was positively correlated with the level ofCD25+Foxp3+Tregs in CD4 +tumor-infiltrating lymphocytes in TNBC.

In contrast to tissue infiltrating Tregs, peripheral blood CD $4+\mathrm{CD} 25+$ Foxp3 + Tregs had no association with any of the clinico-pathological features of TNBC. These findings support the notion that tumor resident Tregs have distinct features that differ from Tregs in peripheral blood. ${ }^{16}$ On the other hand, the proportions of circulating Tregs were found to be associated with an increased occurrence of breast cancer. ${ }^{26}$

The association between the Tregs and the clinicopathological features of TNBC suggested that increasing 
Table 4 Relations Between Peripheral Blood Tregs and the Clinicopathologic Characteristics of Patients with TNBC

\begin{tabular}{|c|c|c|c|c|}
\hline Parameters & $\mathrm{CD4}^{+} \mathrm{T}$ Cells & CD4+CD25 low $T$ Cells & $\mathrm{CD}^{+} \mathrm{CD} 25^{\text {thigh }} \mathrm{T}$ Cells & Tregs \\
\hline \multicolumn{5}{|l|}{ Tumor size $\mathrm{a}^{\mathrm{a}^{*}}$} \\
\hline TI $(n=4)$ & $45.7 \pm 1$ & $19.6 \pm 2$ & $6.2 \pm 2$ & $2.2 \pm 0.05$ \\
\hline$T 2(n=19)$ & $39.1 \pm 2$ & $19.3 \pm 0.8$ & $7.2 \pm 0.6$ & $2.4 \pm 0.1$ \\
\hline T3 $(n=7)$ & $39.6 \pm 1$ & $19.3 \pm 2$ & $7.3 \pm 1$ & $2.2 \pm 0.1$ \\
\hline$p$-value & 0.3 & 0.99 & 0.8 & 0.4 \\
\hline \multicolumn{5}{|c|}{ Lymph node stage ${ }^{a^{*}}$} \\
\hline No $(n=14)$ & $39.6 \pm 2$ & $19 \pm 1$ & $7 \pm 0.7$ & $2.3 \pm 0.2$ \\
\hline$N I(n=14)$ & $39.9 \pm 2$ & $19 \pm 0.9$ & $6.5 \pm 0.7$ & $2.4 \pm 0.1$ \\
\hline N3 $(n=2)$ & $46 \pm 3$ & $20 \pm 1$ & $12.5 \pm 0.9$ & $2.1 \pm 0.08$ \\
\hline$p$-value & 0.7 & 0.97 & 0.07 & 0.8 \\
\hline \multicolumn{5}{|l|}{ Pathologic type** } \\
\hline IDC $(n=28)$ & $39.8 \pm 1$ & $19.2 \pm 0.7$ & $7.1 \pm 0.5$ & $2.3 \pm 0.09$ \\
\hline ILC $(n=2)$ & $43.8 \pm 5$ & $21.2 \pm 3$ & $7.5 \pm 3$ & $2.5 \pm 0.2$ \\
\hline$p$-value & 0.5 & 0.4 & 0.8 & 0.7 \\
\hline \multicolumn{5}{|c|}{ Histological grade ${ }^{a^{*}}$} \\
\hline GI $(n=I)$ & $44.8 \pm 0$ & $26 \pm 0$ & $1 \mathrm{I} .4 \pm 0$ & $2 \pm 0$ \\
\hline $\mathrm{G} 2(n=25)$ & $40.7 \pm 1$ & $19.3 \pm 0.7$ & $6.9 \pm 0.5$ & $2.4 \pm 0.1$ \\
\hline G3 $(n=4)$ & $35 \pm 4$ & $17.9 \pm 2$ & $7 \pm 1$ & $2.3 \pm 0.2$ \\
\hline$p$-value & 0.3 & 0.1 & 0.3 & 0.8 \\
\hline \multicolumn{5}{|l|}{ Type of surgery* } \\
\hline MRM $(n=23)$ & $40.9 \pm 2$ & $19 \pm 0.6$ & $7 \pm 0.6$ & $2.4 \pm 0.1$ \\
\hline $\operatorname{BCS}(n=7)$ & $37.2 \pm 3$ & $19.2 \pm 2$ & $6.8 \pm 0.9$ & $2.3 \pm 0.2$ \\
\hline Simple mast. $(n=1)$ & $44.8 \pm 0$ & $26 \pm 0$ & $1 \mathrm{I} .4 \pm 0$ & $2 \pm 0$ \\
\hline$p$-value & 0.4 & 0.1 & 0.3 & 0.8 \\
\hline \multicolumn{5}{|l|}{ Recurrence** } \\
\hline No $(n=23)$ & $40 \pm 2$ & $19.2 \pm 0.7$ & $6.7 \pm 0.5$ & $2.3 \pm 0.07$ \\
\hline Yes $(n=7)$ & $40.2 \pm 3$ & $19.7 \pm 2$ & $9 \pm 1$ & $2.5 \pm 0.4$ \\
\hline$p$-value & 0.97 & 0.8 & 0.09 & 0.6 \\
\hline
\end{tabular}

Notes: Mean \pm SE, *One-way ANOVA, **Independent sample $t$-test, ${ }^{\mathrm{a} C l a s s i f i e d ~ a c c o r d i n g ~ t o ~ t h e ~ U n i o n ~ f o r ~ I n t e r n a t i o n a l ~ C a n c e r ~ C o n t r o l . ~}$

Abbreviations: IDC, invasive ductal carcinoma; ILC, invasive lobular carcinoma; MRM, modified radical mastectomy; BCS, breast-conserving surgery; mast., mastectomy; G, grade; N, lymph node stage; $\mathrm{T}$, tumor stage.

tumor-infiltrating Tregs was associated with increased tumor size and local recurrence as well as decreased disease-free survival.

Increased frequency of tumor-infiltrating Tregs was observed in the more aggressive BC subset; TNBC and was associated with higher-grade lesions among all studied breast cancer subsets. ${ }^{16}$ Liu et al. ${ }^{31}$ observed increased $\mathrm{CD} 4^{+} \mathrm{CD} 25^{+} \mathrm{Foxp}^{+}$Tregs infiltration in breast cancer tissues and that was associated with high histologic grade, negative estrogen and progesterone receptors status, and overexpression of human epidermal growth factor receptor type 2, along with diminished overall as well as progression-free survivals. On the other hand, Yeong et al. ${ }^{21}$ reported that high number of tumor-infiltrating $\mathrm{CD} 4^{+} \mathrm{CD} 25^{+}$Foxp $^{+}$Tregs in TNBC patients was linked to a higher tumor grade, lymph node status and better prognosis. Increasing the numbers of tumor-infiltrating Tregs may augment local immunosuppressive abilities, suppressing the anti-tumor immunity, thus enhancing tumor growth and invasion, ${ }^{32}$ in addition; early breast cancer has an inflammatory milieu characterized by $\mathrm{mDC}$, Treg, and cancer stem cells (CSC) infiltration. The frequencies of Treg, 

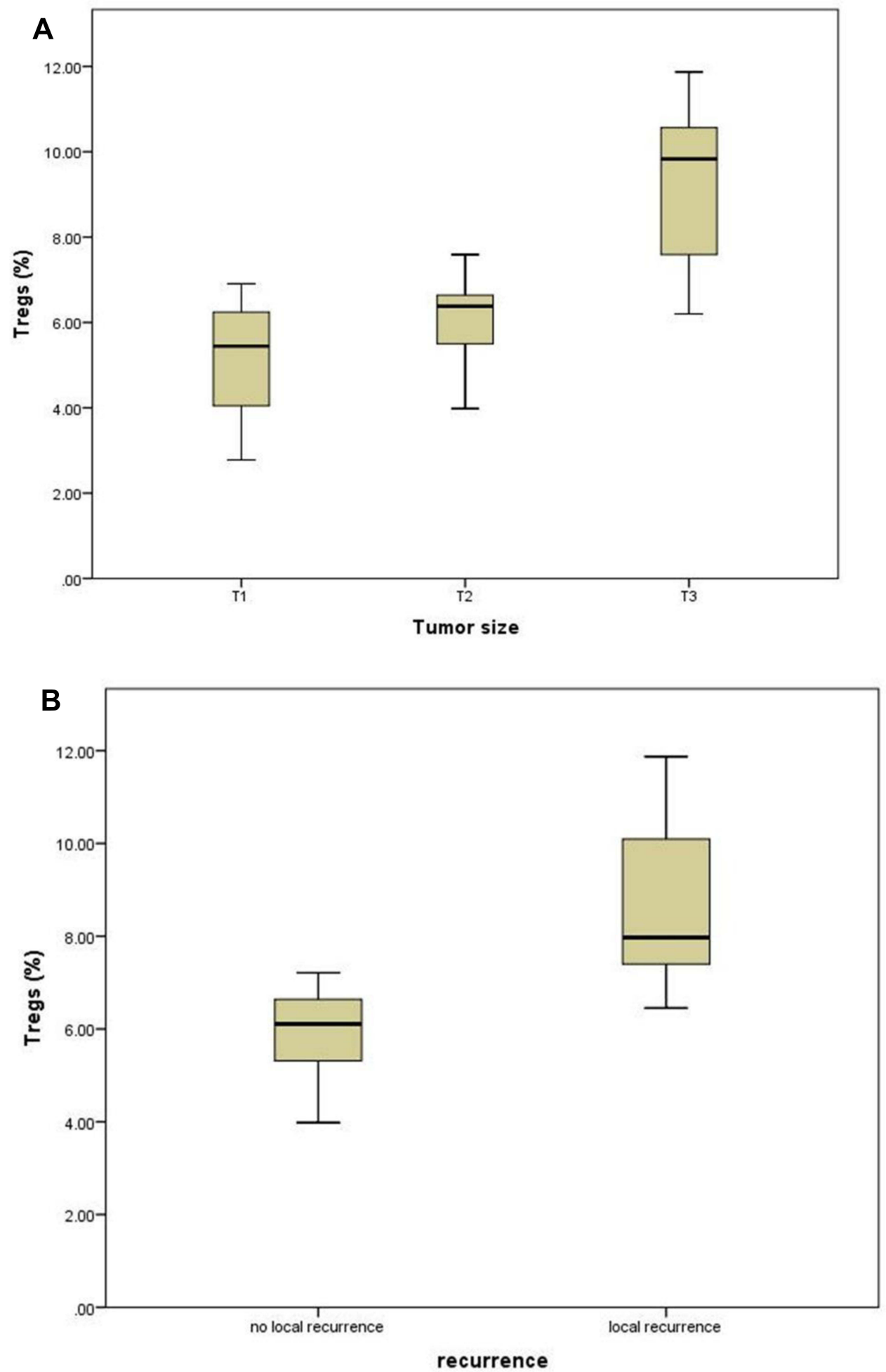

Figure 3 Tumor-infiltrating Tregs showing increasing levels with the increase in the tumor size (A) and in patients with local recurrences (B).

$\mathrm{CSC}$ and $\mathrm{CD} 8 /$ Treg ratio were associated with disease progression including lymph node metastasis. ${ }^{33}$

Moreover, a previous review ${ }^{34}$ proposed that Tregs have cytotoxic capability that may directly kill effector T cell, which may explain the association between Foxp3+ Tregs infiltration and poor recurrence free survival of breast cancer patients. ${ }^{35}$

The study findings support the notion that Tregs can directly contribute to tumor progression rather than they 

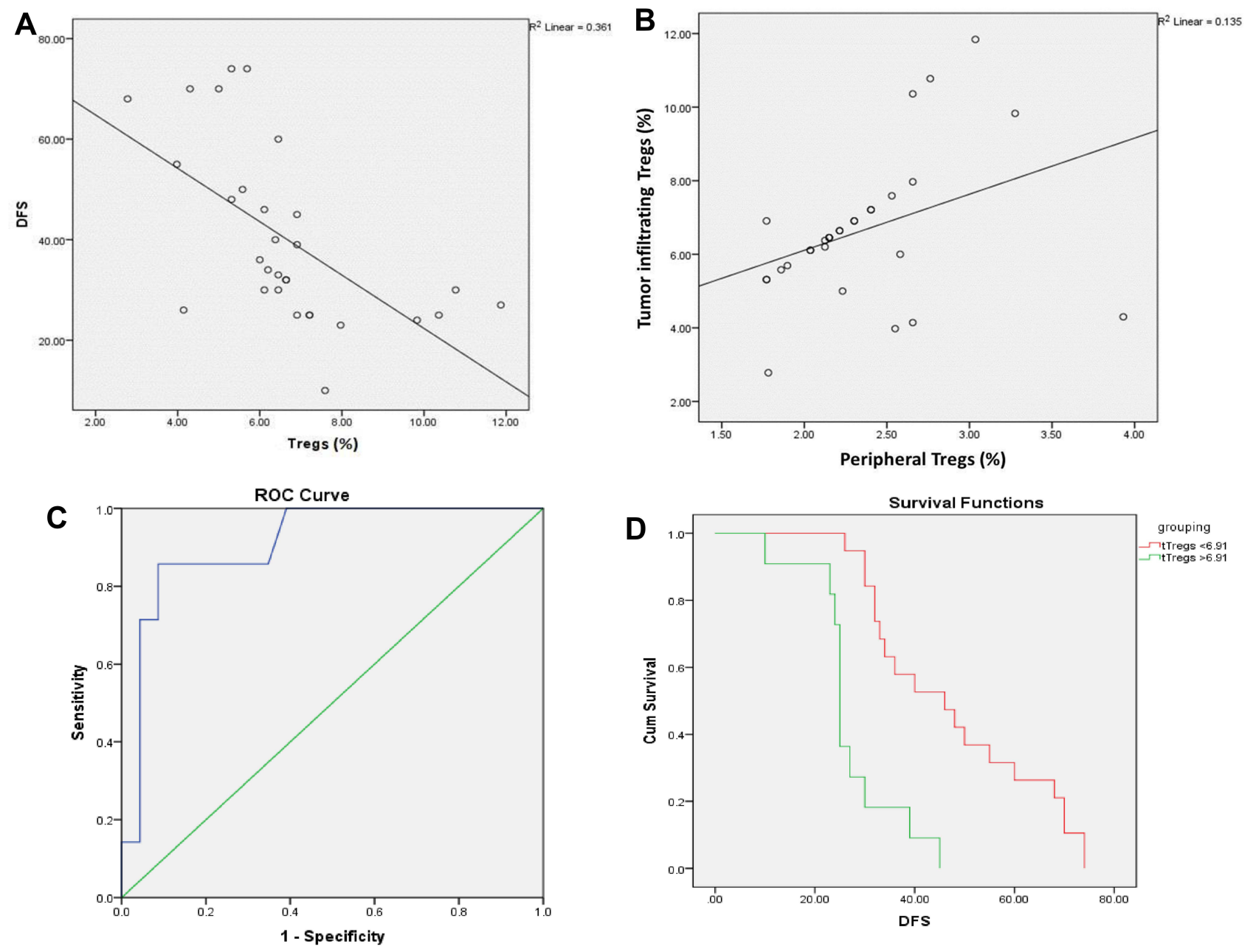

Figure 4 Tumor-infiltrating Tregs (A) correlation with DFS, (B) correlation with peripheral Tregs, (C) accuracy of prediction of DFS period ( $\geq 3$ years) using ROC curve and (D) differences in DFS according to the cutoff value of Tregs.

accumulate in the tumor tissue as a consequences of other immunologic mechanisms controlling tumor progression.

The current study had a number of limitations, the small number of patients was a crucial limitation that was responsible for absence of several statistical relations, and heterogeneity of patients as the study recruited early and locally advanced diseases.

\section{Conclusion}

The findings of the current study support the possibility that TNBC microenvironment conveys specific characteristics on Tregs distinguishing them from those in normal breast tissue or Tregs in peripheral blood, improving the capabilities of tumor-infiltrating Tregs to enhance tumor growth, local recurrence and reduce the DFS. They also suggest the therapeutic value of targeting the function of tumor-infiltrating Tregs in TNBC.

\section{Data Sharing Statement}

All analyzed data are included within the article.

\section{Funding}

There is no funding to report.

\section{Disclosure}

All authors reported no conflicts of interest for this work.

\section{References}

1. Tang J, Yang Z, Wang Z, et al. Foxp3 is correlated with VEGF-C expression and lymphangiogenesis in cervical cancer. World J Surg Oncol. 2017;15:173. 
2. Josefowicz SZ, Lu LF, Rudensky AY. Regulatory T cells: mechanisms of differentiation and function. Annu Rev Immunol. 2012;30:531-564.

3. Shang B, Liu Y, Jiang SJ, Liu Y. Prognostic value of tumor infiltrating FoxP3+ regulatory $\mathrm{T}$ cells in cancers: a systematic review and meta analysis. Sci Rep. 2015;5:15179.

4. Joshi NS, Akama-Garren EH, Lu Y, et al. Regulatory T cells in tumor-associated tertiary lymphoid structures suppress anti-tumor $\mathrm{T}$ cell responses. Immunity. 2015;43:579-590.

5. Pastille E, Bardini K, Fleissner D, et al. Transient ablation of regulatory $\mathrm{T}$ cells improves antitumor immunity in colitis-associated colon cancer. Cancer Res. 2014;74:4258-4269.

6. Ladoire S, Martin F, Ghiringhelli F. Prognostic role of FOXP3+ regulatory $\mathrm{T}$ cells infiltrating human carcinomas: the paradox of colorectal cancer. Cancer Immunol Immunother. 2011;60:909-918.

7. Higgins JP, Thompson SG, Deeks JJ, Altman DG. Measuring inconsistency in meta-analyses. BMJ. 2003;327(7414):557-560.

8. Demir L, Yigit S, Ellidokuz H, et al. Predictive and prognostic factors in locally advanced breast cancer: effect of intratumoral FOXP3+ tregs. Clin Exp Metastasis. 2013;30(8):1047-1062.

9. Takenaka M, Seki N, Toh U, et al. FOXP3 expression in tumor cells and tumor-infiltrating lymphocytes is associated with breast cancer prognosis. Mol Clin Oncol. 2013;1(4):625-632.

10. Bauer KR, Brown M, Cress RD, Parise CA, Caggiano V. Descriptive analysis of estrogen receptor (ER)-negative, progesterone receptor (PR)-negative, and HER2-negative invasive breast cancer, the socalled triple-negative phenotype. Cancer. 2007;109(9):1721-1728. doi:10.1002/cncr.22618

11. Newman LA, Reis-Filho JS, Morrow M, Carey LA, King TA. The 2014 Society of Surgical Oncology Susan G. Komen for the cure symposium: triple-negative breast cancer. Ann Surg Oncol. 2015;22 (3):874-882.

12. Disis ML, Stanton SE. Triple-negative breast cancer: immune modulation as the new treatment paradigm. Am Soc Clin Oncol Educ Book. 2015;35:25-30.

13. Kwa MJ, Adams S. Checkpoint inhibitors in triple-negative breast cancer (TNBC): where to go from here. Cancer. 2018;124:2086-2103.

14. Denkert C, Liedtke C, Tutt A, Minckwitz GV. Molecular alterations in triple-negative breast cancer-the road to new treatment strategies Lancet. 2017;389:2430-2442.

15. Kim S, Lee A, Lim W, et al. Zonal difference and prognostic significance of foxp3 regulatory $\mathrm{T}$ cell infiltration in breast cancer. $J$ Breast Cancer. 2014;17:8-17.

16. Plitas G, Konopacki C, Wu K, et al. Regulatory $\mathrm{T}$ cells exhibit distinct features in human breast cancer. Immunity. 2016;45 (5):1122-1134. doi:10.1016/j.immuni.2016.10.032

17. Wang L, Simons DL, Lu X, et al. Connecting blood and intratumoral $\mathrm{T}_{\text {reg }}$ cell activity in predicting future relapse in breast cancer. Nat Immunol. 2019;20:1220-1230.

18. Mahmoud SM, Paish EC, Powe DG, et al. An evaluation of the clinical significance of FOXP3+ infiltrating cells in human breast cancer. Breast Cancer Res Treat. 2011;127:99-108.

19. Lee S, Cho EY, Park YH, Ahn JS, Y-h IM. Prognostic impact of FOXP3 expression in triple negative breast cancer. Acta Oncol. 2013;52:73-81.

Cancer Management and Research

Publish your work in this journal

Cancer Management and Research is an international, peer-reviewed open access journal focusing on cancer research and the optimal use of preventative and integrated treatment interventions to achieve improved outcomes, enhanced survival and quality of life for the cancer patient.
20. West NR, Kost SE, Martin SD, et al. Tumour-infiltrating FOXP3(+) lymphocytes are associated with cytotoxic immune responses and good clinical outcome in estrogen receptor-negative breast cancer. Br J Cancer. 2013;108:155-162.

21. Yeong J, Thike AA, Lim JCT, et al. Higher densities of Foxp3+ regulatory $\mathrm{T}$ cells are associated with better prognosis in triple-negative breast cancer. Breast Cancer Res Treat. 2017;163:21-35.

22. Zhang L, Wang XI, Ding J, et al. The predictive and prognostic value of Foxp3+/CD25+ regulatory T cells and PD-L1 expression in triple negative breast cancer. Ann Diagn Pathol. 2019;40:143-151.

23. Foulkes WD, Smith IE, Reis-Filho JS. Triple-negative breast cancer. N Engl J Med. 2010;363:1938-1948.

24. Denkert C, Von Minckwitz G, Darb-Esfahani S, et al. Tumor-infiltrating lymphocytes and prognosis in different subtypes of breast cancer: a pooled analysis of 3771 patients treated with neoadjuvant therapy. Lancet Oncol. 2018;19:40-50.

25. Kim ST, Jeong $\mathrm{H}$, Woo $\mathrm{OH}$, et al. Tumor-infiltrating lymphocytes, tumor characteristics, and recurrence in patients with early breast cancer. Am J Clin Oncol. 2013;36:224-231.

26. Wang R, Huang K. CCL11 increases the proportion of CD4+CD25 + Foxp3+ Tregs and the production of IL- 2 and TGF- $\beta$ by CD4+ T cells via the STAT5 signaling pathway. Mol Med Rep. 2020;21.6:2522-2532.

27. Syed Khaja AS, Toor SM, El Salhat H, et al. Preferential accumulation of regulatory $\mathrm{T}$ cells with highly immunosuppressive characteristics in breast tumor microenvironment. Oncotarget. 2017;8:3315933171.

28. Huehn J, Siegmund K, Lehmann JC, et al. Developmental stage, phenotype, and migration distinguish naive- and effector/memorylike CD4+ regulatory T cells. J Exp Med. 2004;199:303-313.

29. Levine AG, Arvey A, Jin W, Rudensky AY. Continuous requirement for the TCR in regulatory $\mathrm{T}$ cell function. Nat Immunol. 2014;15:1070-1078.

30. Cai B, Ma P, Ding P, Sun D-W, Bu Q, Zhang J. Composition and plasticity of triple-negative breast carcinoma-infiltrating regulatory $\mathrm{T}$ cells. APMIS. 2020;128:260-269.

31. Liu F, Lang R, Zhao J, et al. CD 8+ cytotoxic T cell and FOXP3+ regulatoryT cell infiltration in relation to breast cancer survival and molecular subtypes. Breast Cancer Res Treat. 2011;130:645-655.

32. Xue D, Xia T, Wang J, Chong M, Wang S, Zhang C. Role of regulatory $\mathrm{T}$ cells and $\mathrm{CD} 8^{+} \mathrm{T}$ lymphocytes in the dissemination of circulating tumor cells in primary invasive breast cancer. Oncol Lett. 2018;16(3):3045-3053. doi:10.3892/ol.2018.8993

33. Solis-Castillo LA, Garcia-Romo GS, Diaz-Rodriguez A, et al. Tumor-infiltrating regulatory $\mathrm{T}$ cells, CD8/Treg ratio, and cancer stem cells are correlated with lymph node metastasis in patients with early breast cancer. Breast Cancer. 2020;27(5):837-849.

34. Lu L, Barbi J, Pan F. The regulation of immune tolerance by FOXP3. Nat Rev Immunol. 2017;17(11):703-717. doi:10.1038/nri.2017.75

35. Zhou Y, Shao N, Aierken N, et al. Prognostic value of tumor-infiltrating Foxp3+ regulatory $\mathrm{T}$ cells in patients with breast cancer: a meta-analysis. J Cancer. 2017;8(19):4098-4105. doi:10.7150/ jca. 21030
The manuscript management system is completely online and includes a very quick and fair peer-review system, which is all easy to use. Visit http://www.dovepress.com/testimonials.php to read real quotes from published authors. 